\title{
PEMBERDAYAAN KELOMPOK WANITA TANI (KWT) : PENGOLAHAN JAGUNG DI DUSUN KARANGNONGKO DESA NGLORO KECAMATAN SAPTOSARI KABUPATEN GUNUNG KIDUL
}

\author{
THE EMPOWERMENT OF WOMEN FARMER GROUP : CORN PROCESSING IN \\ KARANONGKO, NGLORO VILLAGE, SAPTOSARI DISTRICT, GUNUNG KIDUL
}

\author{
${ }^{1)}$ Desi Susilawati, ${ }^{2)}$ Putri Rachmawati \\ ${ }^{1)}$ Akuntansi Program Vokasi, Universitas Muhammadiyah Yogyakarta \\ ${ }^{2}$ Teknik Mesin Program Vokasi, Universitas Muhammadiyah Yogyakarta \\ Jl. Brawijaya, Tamantirto, Kasian, Bantul, Yogyakarta
}

Email: desisusilawati46@yahoo.com

\begin{abstract}
ABSTRAK
Dusun Karangnongko, Desa Ngloro, Kecamatan Saptosari, Kabupaten Gunung Kidul memiliki hasil panen jagung dan singkong yang berlimpah. Namun hasil panen ini belum diolah oleh masyarakat secara optimal. Dusun Karanongko memiliki potensi kewirausahaan, karena ada beberapa kelompok wanita tani yang sudah memiliki usaha kecil seperti olahan Kripik Tempe, namun belum ada kelompok usaha yang mengolah jagung. Pelaksanaan KKN PPM ini menggunakan metode ESD (Education for Sustainable Development). ESD adalah metode pembelajaran untuk mendukung pembangunan berkelanjutan, yaitu jenis pembelajaran yang memberikan kesadaran jiwa wirausaha yang inovatif dan kreatif. Program yang dilakukan meliputi: 1) Ceramah tentang pentingnya kegiatan pasca panen, 2) penyuluhan untuk meningkatkan jiwa wirausaha, 3)Pelatihan dan praktik mengolah jagung menjadi eggroll, 4) Pelatihan Packaging /labelling sehingga kemasan menjadi lebih menarik dan memasarkan produk. Hasil kegiatan pengabdian ini adalah tumbuhnya keasadaran keluarga berjiwa wirausaha yang mandiri, meningkatnya pengetahuan dan keterampilan kelompok wanita tani dalam mengolah makanan berbahan dasar jagung,terjalin kerjasama dengan UKM Putri 21 menjadi pemasok jagung dan singkong.
\end{abstract}

Kata kunci: Olahan singkong dan jagung; Packaging/labeling; Education for Sustainable Development

\begin{abstract}
Karangnongko Hamlet, Ngloro Village, Saptosari District, Gunung Kidul Regency has an abundant harvest of corn and cassava. However, this harvest has not been optimally processed by the community. Karanongko Hamlet has entrepreneurial potential because there are several groups of women farmers who already have a small business, such as processed Kripik Tempe, but there are no business group processes corn. The Implementation of the KKN PPM used the ESD (Education for Sustainable Development) method. ESD is a learning method to support sustainable development, which is a type of learning that provides an innovative and creative awareness of the entrepreneurial spirit. Programs carried out include: 1) Lectures on the importance of post-harvest activities, 2) counseling to improve entrepreneurship, 3) Training and practice of processing corn into eggrolls, 4) Packaging/labeling training so that packaging becomes more attractive and markets products. The results of these community service activities are the growing awareness of independent entrepreneurial families, increasing the knowledge and skills of farmer women's groups in processing corn-based food, cooperating with UKM 21 becoming a supplier of corn and cassava.
\end{abstract}

Keywords: Processed cassava and corn; Packaging/labeling; Education for Sustainable Development

Submitted : 26 Juni 2019 Revision : 7 November 2019 Accepted : 20 Februari 2020 


\section{PENDAHULUAN}

Desa Ngloro, terletak dikecamatan Saptosari, Gunung Kidul, Daerah Istimewa Yogyakarta berjarak 56,7 km dari Universitas Muhammadiyah Yogyakarta dengan jarak tempuh 1 jam, 30 menit. Demografi masyarakat Desa Ngloro terdiri dari laki- laki 1.551 dan perempuan 1.646. Dengan demikian total jiwa masyarakat Desa Ngloro adalah 3.197 jiwa. Di Desa Ngloro terdapat 6 Dusun yaitu Dusun Karangnongko, Dusun Tekik, Dusun Pringsurat, Dusun Ngloro, Dusun Pule, dan Dusen Gebang. Desa Ngloro dipimpin oleh Seorang Lurah yaitu Bapak Hery Yuliyanto. Pedukuhan Karangnongko yang merupakan salah satu pedukuhan didesa Ngloro dipimpin oleh seorang dukuh yaitu Bapak Sukadi. Berikut disajikan Struktur organisasi dan tatakerja Pemerintahan Desa Ngloro.

Berdasarkan observasi dan diskusi didapatkan hasil :

"Untuk lebih meningkatan perekonomian dan terciptanya lapangan pekerjaan, pemerintah Desa dan Pemerintah Propinsi Gunung Kidul telah mencanangkan program Kawasan Ekonomi Khusus yang meliputi 3 kecamatan yaitu Kecamatan Sapto Sari, Kecamatan Panggang dan Kecamatan Purwosari. Setelah dilakukan rembug diantara Perangkat Kecamatan Saptosari, Perangkat Desa se Kecamatan Saptosari telah ditentukan akan dibangun Kawasan Taman Buah Alpukat di Desa Ngoro dan berlokasi di dusun Karangnongko. Kawasan ekonomi Khusus ini memiliki Grand Design tidak hanya dibangun taman buah, rencananya akan dibangun Homestay, Bungalow dan Resort yang tentunya tidak merusak lingkungan dan alam. Perlu saya infokan bahwa Pendirian Homestay, Bungalow dan Resort sudah memasuki tahap perizinan."

Kawasan Ekonomi Khusus merupakan program Pemerintahan kabupaten Gunung Kidul dikemudian akan menjadi destinasi wisata yang mampu meningkatkan perekonomian masyarakat, harus mendapat dukungan dari masyarakat. Salah satu bentuk dukungan adalah mempersiapkan diri dan bekal untuk ikut berpartisipasi dalam kegiatan ekonomi. Metode Pemberdayaan merupakan salah satu pendekatanpembangunan dalam proses penguatan ekonomi dan sosial untuk meningkatkan kesejahteraan hidup masyarakat, utamanya di pedesaan (Daulay, 2006). Salah satunya adalah pentingnya peningkatkan jiwa wirausaha mandiri untuk mengolah potensi alam /potensi hasil tani sehingga mampu meningkatkan kualitas produk, penghasilan keluarga menuju kesejahteraan keluarga

Terlihat Jelas hubungan antara program Kawasan Ekonomi Khusus dengan peningkatan perekonomian keluarga sehingga mampu mewujudkan keluarga yang sejahtera. Hal ini sejalan dengan Gerakan Pemberdayaan Masyarakat dan Kesejahteraan Keluarga (PMKK) adalah gerakan nasional dalam pembangunan masyarakat yang tumbuh dari bawah yang pengelolaanya dari, oleh dan untuk masyarakat menuju terwujudnya keluarga yang beriman, bertaqwa kepada Tuhan Yang Maha Esa, berakhlak mulia, berbudi luhur, sehat, sejahtera, maju, mandiri, kesejahteraan, keadilan gender, kesadaran hukum dan peduli kepada lingkungan. Bagian dari PMKK adalah pemberdayaan keluarga. Pengertian pemberdayaan keluarga adalah segala upaya bimbingan dan pembinaan agar keluarga dapat hidup sehat, sejahtera, maju dan mandiri menujuterpenuhinya kebutuhan dasar manusia dari setiap anggota keluarga secara material, sosial, mental dan spiritual sehingga dapat hidup layak sebagai manusia yang bermanfaat sehingga terwujud keluarga yang sejahtera.

Permasalahan yang dihadapi masyarakat adalah hasil pertanian jagung dan singkong yang melimpah namun pengolahan belum optimal dari unsur produksi dan pemasaran. Hasil panen singkong maupun jagung masih dijual dalam bentuk mentah. Jagung langsung dijual setelah di pipil kepada tengkulak dengan harga murah. Singkong hanya diolah menjadi gaplek lalu dijual. Jagung mempunyai peranan yang penting untuk industri pangan dan pakan ternak. Pemnafaatan jagung sebagai bahan baku produksi pangan dapat memberikan nilai tambah/ positif bagi komoditas jagung. Hasil dari penjualan tersebut tidak memiliki nilai jual yang tinggi meski proses memanen membutuhkan tenaga dan waktu yang banyak. Oleh karena itu Warga Masyarakat khususnya Ibu-Ibu PKK membutuhkan keterampilan bagaimana mengolah jagung dan singkong 
menjadi olahan makanan yang bernilai jual tinggi sehingga dapat meningkatkan penghasilan keluarga. Berikut identifikasi permasalahan mitra sebagai berikut : 1) Masyarakat mengolah singkong menjadi gaplek dan jagung dipipil, sehingga belum menjadi olahan bernilai tambah. Saat ini ibuibu PKK hanya merebus jagung untuk dikonsumsi keluarga dan singkong menjadi geplek. 2) Saat ini Kelompok Wanita Tani kurang memiliki pengetahuan dan keterampilan bagaimana mengolah jagung menjadi tepung jagung dan singkong menjadi tepung singkong (Mocaf), 3) Kurangnya pengetahuan tentang pengemasan panganan agar panganan bebas dari ketengikan dan lebih tahan lama, 4) Pemahaman jiwa wirausaha agar tercipta ekonomi keluarga yang mandiri masih kurang.

Selain potensi alam berupa hasil panen yang melimpah, Dusun Karangnongko memiliki potensi besar untuk pengembangan dusun agar lebih baik. Adapun potensi yang ada meliputi potensi ekonomi, potensi kewirausahaan, dan potensi keorganisasian/ Lembaga Masyarakat dan potensi sosial budaya.

Ibu-ibu yang tidak melakukan kegiatan pertanian memilih untuk menjadi ibu rumah tangga atau berdagang. Beberapa kelompok usaha kecil telah ada di Dusun karangnongko seperti dengan produk berupa Kripik Tempe dan Kripik Singkong, namun belum mengolah jagung untuk menjadi produk yang bernilai ekomomis tinggi.

Solusi untuk mengatasi permasalahan mitra adalah memberikan pemahaman untuk meningkatkan jiwa wirausaha sehingga terwujud kemandirian ekonomi keluarga dengan pemanfaatan potensi panen berupa jagung yang diolah lebih lanjut sehingga bernilai jual tinggi,

\section{METODE}

Langkah-langkah pelaksanaan kegiatan dimulai dari observasi yang dilakukan pihak pengabdi dengan Lembaga Pengembangan Penelitian dan Pengabdian pada Masyarakat Universitas Muhammadiyah Yogyakarta (LP3M UMY) bahwa Dusun Karangnongko memiliki problematika pendapatan ekonomi keluarga masih rendah dan keterampilan untuk mengolah atau kegiatan pasca panen jagung dan singkong yang masih belum optimal serta masih kurang pemahaman tentang wirausaha mandiri untuk menwujudkan ekonomi keluarga yang mandiri.

Mitra pada kegiatan ini adalah Kelompok Tani Guyub Rukun, Ibu PKK Dusun Karangnongko. Pelaksanaan KKN-PPM menggunakan metode ESD (Education for Sustainable Development). ESD adalah metode pembelajaran untuk mendukung pembangunan berkelanjutan, yakni jenis pembelajaran yang memberikan kesadaran dan kemampuan untuk mendorong masyarakat berpikir konstruktif dan kreatif dalam menghadapi tantangan global serta menciptakan masyarakat tangguh secara berkelanjutan. ESD memiliki 3 pilar yang sangat mendasar yaitu ekologi, ekonomi dan sosial. Ketiga pilar tersebut saling berhubungan dan keterkaitan satu dengan yang lainnya (Supratikno, 2004).

Pada tahapawal atau perencanaan Tim Pengabdi melakukan observasi dan wawancarasecaralangsungdenganmitra yaitu Bapak Lurah Desa Ngloro dan segenap Perangkat Desa.Kegiatan KKN-PPMini dimulai pada tgl 14 Januari 2019 hingga 15 Februari 2019.Metode yang diterapkan dalam pemberdayaan masyarakat pada kegiatan pengabdian masyarakat ini adalah sebagai berikut : 1) Ceramah tentang pentingnya penanganan pasca panen salah satunya pengolahan jagung dan penyuluhan untuk meningkatkan jiwa wirausaha, 2) Pelatihan dan praktik mengolah jagung menjadi eggroll dengan higeinis dan pelatihan pengoperasian alat produksi dan pengemasan, 3) Pelatihan Packaging/labelling sehingga kemasan menjuadi lebih bagus dan menarik.

\section{HASIL DAN PEMBAHASAN}

Pelaksanaan program ini akan melibatkan unsur masyarakat desa, terutama kelompok Wanita Tani Tani Guyub Rukun, PKK serta Karang Taruna Manunggal. Tujuannya untuk kaderisasi, dimana tim dan masyarakat akan bersama-sama berpartisipasi melaksanakan program tersebut, sehingga nantinya, ketika KKN PPM ini telah dijalankan dan berakhir tidak berhenti sampai disitu saja, tapi tetap terus berjalan dan ada Rencana Tindak Lanjut (RTL).Selama Kurang lebih sebulan KKN PPM UMY di Dusun Karangnongko dilaksanakan 3 program, yaitu: 
1. Penyuluhan untuk meningkatkan jiwa wirausaha ekonomi kreatif dan mandiri

Tim KKN -PPM beserta perwakilan ibuibu PKK (3 ibu mewakili masing-masing RT) melihat secara langsung d praktik pembuatan tepung singkong (mocaf) UKM Putri - 21 di Playen. Pada kesempatan ini Ketua UKM Putri 21 yaitu ibu Suti Rahayu menjelaskan awal pendirian UKM dengan segala tantangan, hambatan dan perjuangan untuk pantang menyerah sehingga kini UKM Putri 21 sangat maju dan memiliki lebih dari 50 produk unggulan dari olahan jagung dan singkong, pare dan bonggol pisang, serta berbagai mie dari tepung singkong. Kegiatan ini telah meningkatkan pemahaman peserta akan pentingnya membangun motivasi dan semangat jiwa wirausahan sehingga mampu mandiri dan meningkatkan perekonomian keluarga.

Pada kesempatan ini Ibu Suti Rahayu menjelaskan bagaimana cara membuat tepung singkong dan tepung jagung. Untuk memperpanjang umur simpan singkong danjagung serta dapat meningkatkan nilai ekonomis nya yaitu diolah menjadi tepung dan olahan tepung itu sendiri menjadi panganan. Tepung mempunyai beberapa keunggulan, antara lain lebih mudah dalam penyimpanan, umur simpan lebih lama, penggunaanya lebih luas, lebih mudah difortifikasi, dan lebih mudah bercampur dengan bahan lain (Marta, 2011). Oleh sebab itu salah satu Outcome kegiatan ini adalah meningkatkan semangat ibu-ibu PKK dusun Karangnongko untuk memulai usaha mandiri dan kreatif dari olahan jagung dan singkong. Tim Pengabdi berhasil memfasilitasi kerjasama bagi warga dusun Karangnongko dengan UKM Putri 21 untuk menjadi pemasok singkong dan jagung yang selanjutnya menjadi tepung singkong (Mocaf) dan tepung jagung di UKM Putri -21.

Pelatihan tentang proses produksi tepung singkong memberikan peningkatan pengetahuan dan keterampilan keberdayaan masyarakat, hal ini dapat dilihat dimana sebelum dilakukan pelatihan semua anggota kelompok mitra belum mampu mengetahui cara membuat tepung singkong dan jagung setelah dilakukan pelatihan, maka 90,57\% sudah mampu memahami proses pembuatan tepung singkong dan tepung jagung dan bersedia menjadi pemasok singkong dan jagung.
Tim Pengabdi juga menyusun dokumen cara mengolah singkong tidak hanya menjadi keripik atau geplek tetapi juga menjadi mie dari tepung singkong. Outcome dari kegiatan ini adalah terjalin kerjasama dengan UKM Putri 21 Playen dengan warga yang akan mengolah singkong menjadi tepung singkong (Mocaf), jagung menjadi tepung jagungdan menjadi pemasok singkong dan jagung bagi UKM Putri 21.

\section{Pelatihan dan Praktik Pengolahan Jagung Menjadi Eggroll}

Program ini dapat menjadi sebuah inovasi baru dan meruupakan potensi usaha untuk meningkatkan perekonomian warga setempat. Hasil panen jagung yang telah laku seharga 3000 sampai $\mathrm{Rp}$ 4.000 rupiah perkilonya. Dengan adanya pelatihan pembuatan dan pengemasan eggroll, dengan menggunakan alat produksi dan alat pengemasan yang telah disediakan, ini, mampu meningkatkan keterampilan peserta sehingga dapat memproduksi Eggroll jagung dalam skala rumah tangga dan mampu meningkatkan perekonomian keluarga sehingga tercipta ekonomi keluarga yang mandiri. Olahan pangan dari hasil panen jagung kebun warga setempat dapat menjadi produk yang bernilai ekonomi tinggi. Kegiatan praktik ini, disambut dengan sangat antusias oleh warga terutama para ibu-ibu sangat terlihat ketika proses pelatihan praktik pembuatan atau proses produksi eggroll jagung, peserta memberikan respon yang sangat aktif. Proses produksi dimulai dengan persiapan bahan baku dan peralatan.

Kegiatan ini tidak hanya terhenti pada proses produksi namun pengabdi membantu meningkatkan pemahaman tentang bagaimana design kemasan dan pemilihan bahan dan bentuk kemasan yang untuk menjaga kualitas produk.

\section{Penyuluhan Packaging \& Labeling}

Program Pengembangan Produk lokal ini mencakup juga tahap packaging \& labeling. Sebagai strategi untuk menambah nilai produk dan menarik minat konsumen. Kegiatan pelatihan ini 
berupa praktek pengemasan produk eggroll jagung berupa pemberian label merek dan pelatihan cara pengoperasioan alat pengemasan.Tujuan dilaksanakannya kegiatan ini tidak lain agar masyarakat mampu menciptakan nama merek dagang yang mudah diingat dan kemasan yang tahan lama sehingga eggroll jagung tidak mudah tengik atau berubah rasa. Kegiatan ini menghasilkan output yaitu produk eggroll jagung dengan pengemasan yang rapi beserta pemberian labeling, disepakati nama merek adalah Waterfall pada kemasan produk. Pemilihan nama ini karena ketika kita mengkonsumsi eggroll ada reruntuhan. Produk di kemas dalam plastik Standing Pouch dengan berat bersih 200 gram. Kemasan yang dipilih agar produk tidah mudah hancur. tetap renyah karena didukung kemasan yang kaku dan tidak mudah tengik. Pelatihan Kemasan sekaligus pelabelan menjelaskan antara lain informasi tentang produk seperti komposisi bahan baku, tanggal produksi dan expired date. Manfaat labelling adalah sebagai strategi untuk menambah nilai produk dan menarik minat konsumen agar produk jadi menarik perhatian konsumen, nama produk mudah diingat sehingga dapat meningkatkan daya jual produk (Mardiana \& Puspitasari, 2018).

Pelatihan ini telah meningkatkan pengetahuan dan keterampilan ibu-ibu PKK dalam bidang pengolahan pangan dari jagung sehingga jagung yang semula hanya dipipil dan langsung dijual dapat dikembangkan menjadi olahan pangan ynag bernilai jual tinggi. Evaluasi atas pelaksanaan kegiatan telah dilakukan dan hasil evaluasi tersaji pada tabel 1 .
Tabel 1. Hasil Evaluasi Kegiatan

\begin{tabular}{|c|c|c|}
\hline \multirow{2}{*}{$\begin{array}{l}\text { Pengetahuan \& } \\
\text { Keterampilan }\end{array}$} & \multicolumn{2}{|c|}{ Penguasaan Keterampilan } \\
\hline & Pre test & Post test \\
\hline $\begin{array}{l}\text { 1. Pemahaman peserta } \\
\text { tentang cara } \\
\text { membuat tepung } \\
\text { singkong }\end{array}$ & $\begin{array}{l}\text { Kurang } \\
\text { Faham }\end{array}$ & Faham \\
\hline $\begin{array}{ll}\text { 2. } & \begin{array}{l}\text { Pemahaman peserta } \\
\text { tentang cara } \\
\text { membuat tepung } \\
\text { jagung }\end{array} \\
\text { 3. } & \begin{array}{l}\text { Pemahaman peserta } \\
\text { tentang bahan baku } \\
\text { eggroll jagung }\end{array} \\
\text { 4. } & \text { Keterampilan peserta } \\
\text { tentang cara } \\
\text { membuat eggroll } \\
\text { jagung } \\
\text { Keterampilan peserta } \\
\text { untuk } \\
\text { mengoperasikan alat } \\
\text { kemasan } \\
\text { 6. Pemahaman peserta } \\
\text { Packaging \& } \\
\text { Labelling } \\
\text { 7. Pemahaman jiwa } \\
\text { wirausaha }\end{array}$ & 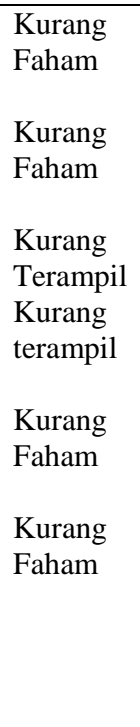 & $\begin{array}{l}\text { Faham } \\
\text { Terampil } \\
\text { Terampil } \\
\text { Faham }\end{array}$ \\
\hline
\end{tabular}

\section{SIMPULAN}

Kelompok Wanita Tani memperoleh pengetahuan dan meningkatnya pemahaman serta keterampilan untuk mengolah jagung dan singkong sehingga memiliki nilai jual tinggi. Meningkatnya jiwa wirausaha bagi KWT untuk membuka usaha bersama olahan jagung sehingga dapat meningkatkan perekonomian keluarga dan mandiri. Berdasarkan hasil evaluasi kegiatan, maka terdapat peningkatan kapabilitas keterampilan dan pengetahuan para anggota kelompok, diketahui sebanyak 93,66\% anggota kelompok wanita tani telah mampu membuat eggroll jagung. 


\section{UCAPAN TERIMA KASIH}

Ucapan terima kasih disampaikan kepada Pimpinan UMY dan LP3M UMY yang telah memberikan kesempatan dan bantuan pendanaan untuk terlaksananya kegiatan ini. Terima kasih juga kami sampaikan kepada Bapak Lurah Hery Yulianto beserta jajaran perangkat Desa Ngloro, Bapak Sukadi selaku Kadus Karangnongko dan seluruh warga Desa Ngoro. Tidak lupa pula kami mengucapkan terima kasih kepada mahasiswa KKN UMY kelompok 093 yang telah berpartisipasi, bekerjasama dengan baik dan berupaya penuh sehingga kegiatan KKN-PPM ini terlaksana.

\section{DAFTAR PUSTAKA}

Daulay, H. (2006). Pemberdayaan Perempuan : Studi Kasus Pedagang Jamu Di Gedung Johor Medan, Jurnal Harmoni Sosial, 1 (1), 7-14
Mardiana, C., Puspitasari, R., (2018), Pengembangan Desain Produk Unggulan IKM di Kabupaten Malang Jawa Timur yang Berdaya saing Tinggi, Jurnal Terob, 1 ( Oktober)

Marta, H. (2011). Sifat Fungsional Dan Reologi Tepung Jagung Nikstamal Serta Contoh Aplikasinya Pada Pembuatan Makanan Pendamping ASI. Bogor: Institut Pertanian Bogor

Supratikno, H., (2004). 'The development of SME Clusters in Indonesia', dalam D. Hewand L.W. Nee (eds), Entrepreneurship and SMEs in Southeast Asia, ISEAS. 